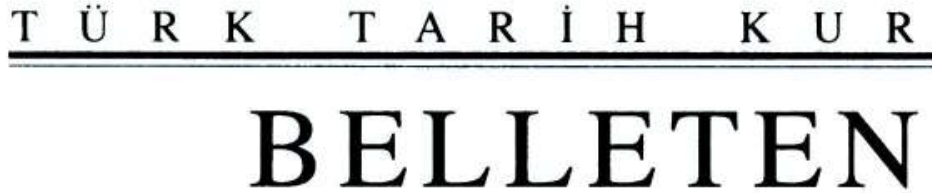

\section{TELL MINAR VE GIREMIRA, NUSAYBİN BÖLGESİ'NDE YER ALAN İKI NINIVE 5 MERKEZI}

\section{BORA UYSAL *}

Kuzey Mezopotamya (Irak'ın kuzeyindeki Dohuk, Musul, Erbil, Kerkük, Süleymaniye ve Diyala bölgeleri) ve Kuzeydoğu Suriye (Yukarı ve kısmen de Orta Habur bölgeleri) bölgelerinin, M.Ö. 3. bindeki en problemli konularından birini olușturan Ninive 5 kültürü; bezemesiz, boya bezemeli ya da çizi-oyma bezemeli olarak karşımıza çıkan seramik grupları ile tanınmaktadır ${ }^{\prime}$. Ninive 5 terimi, söz konusu seramik türünü ifade ettiği gibi, ele geçtiği dönemi ve ilgili malzemeyi üreten kültürü tanmmlayan bir anlam da taşımaktadır ${ }^{2}$. Geç Uruk seramiğinden geliştiği düşünülen Ninive 5 seramiğinde, zengin motif ve kompozisyonlarm görüldüğü bezemeli örnekler ince bir işçiliğe sahiptir. Boya bezemeli seramik, çizi-oyma bezemeli seramiğe göre daha erken bir evreye aittir. Bezemesiz seramik konusunda ise belirgin bir tarihlendirme yapılamamaktadır ${ }^{3}$.

Mardin ili Nusaybin ilçesinde yer alan Girnavaz'da, Prof. Dr. Hayat Erkanal başkanlığında 1982-1991 yılları arasında gerçekleştirilen kazılar, bölgenin Mezopotamya ve Suriye kültürleri ile ilişkilerini ortaya koyan önemli bilgiler sağlamıştır ${ }^{-1}$. Geç Uruk Devri'nden Geç Asur Devri'nin sonlarına kadar kesintisiz yerleşim gösteren bu merkezde, Ninive 5 kültürü de

- Yrd. Doç. Dr. Bora Uysal, Hacettepe Üniversitesi, Edebiyat Fakültesi, Arkeoloji Bölümü. 06800, Beytepe, Ankara. borau@ hacettepe.edu.tr

Rova 1988, 14-21, 201-12; Gut 1995, 267-269.

"Mallowan 1964, 142-143; Scwartz 1985, 53; Roaf and Killick 1987, 200; Rova 1988, 7.

3 Schwartz 1985, 60; Killick 1986, 234; Rova 1988, 141-147, 183; 2003b, 11-16; Numoto 1991. 88-92; 1998; Roaf ve Killick 2003, 74-75.

A. Erkanal 1984; Erkanal ve Erkanal 1989; H. Erkanal, 1984; 1985; 1986; 1988a; 1988b; $1989 ; 1990 ; 1991 a ; 1991 b ; 1998 ; 2000 ;$ Akyurt et. al. 1993. 
kuvvetli bir biçimde temsil edilmektedir ${ }^{5}$. Buna karşılık, Girnavaz'ın önemi komşu bölgelerde çalıșmalar yapan bilim adamları tarafindan çok geç fark edilmiș ve son yıllarda önem kazanmaya bașlamıștıri ${ }^{\text {i }}$.

Girnavaz'daki kazı çalışmaları devam ederken, bölgede sımırlı yüzey araștırmaları da yapılmıștur. Bu merkezin hemen doğusunda sıralanan bir dizi yerleşim, Ninive 5 kültürü konusunda büyük önem taşımaktadır (Harita). Bunlardan ilki, Nusaybin'in $8 \mathrm{~km}$. kuzeydoğusunda Duruca beldesinde bulunan Kertvin'dir ${ }^{7}$. Tepeüstü köyündeki Tell Minar 22 km. ve Girmeli beldesinin altunda kalan Giremira $30 \mathrm{~km}$. kuzeydoğudadır ${ }^{8}$. Her iki merkezde de, günümüz yerleşmelerinin neden olduğu ağır bir tahribat söz konusudur. Daha iyi korunduğu söylenebilecek Tell Minar'in güneybatı yamacında evler bulunmaktadır. Bu evlere ulaşım, höyüğün kuzey kısmından açılan bir yol ile sağlanmıştır (Resim 1-2). Giremira çok daha kötü bir durumdadır. Höyüğün güney yarısı tamamen evlerle kaplanmışur. Kuzey kesimi ise açılan yollar ve toprak alınması nedeniyle tahrip olmaktadır (Resim 3-4).

Tell Minar ve Giremira'da, Ninive 5 seramiği ile birlikte, yine M.Ö. 3. bine ait basit yalın seramik, metalik seramik, M.Ö. 2. bine ait Habur seramiği ve M.Ö. 1. bine ait Geç Assur seramiği de bulunmaktadır. Bunlara ek olarak, Helenistik, Roma ve Ortaçağ dönemlerine ait parçalar da bulunmuştụr. Calışma kapsamında değerlendirilen Ninive 5 seramiği örnekleri 24 parçadan oluşmaktadır. Bunlardan 11'i Tell Minar ve 13'ü Giremira'dan ele geçmiştir. Her iki merkezden de 4'er parça çizi-oyma bezemelidir. Çok ince ve ince nitelikli bir hamur yapısına sahip olan malzeme; çanak, bardak ve çömlek formundaki ağız kenarı parçaları, dip parçaları ve bezemeli gövde parçaları olmak üzere beş grupta toplanmaktadır". Parçaların formları, bezeme kompozisyonları ve hamur yapıları, Girnavaz ve Kertvin'den ele geçen buluntular ile büyük bir benzerlik göstermektedir ${ }^{10}$.

${ }^{5}$ Devam 1988; Uysal 1998. Girnavaz Ninive 5 seramiği tarafimdan yayına hazırlanmaktadır. Bu konu, daha önce Türk-Amerikan Ilmi Arașturmalar Derneği'nin (American Research Institute in Turkey, ARIT) 1995 yılında verdiği "Doktora Bursu" ile desteklenmiștir. Halen, Hacettepe Üniversitesi Bilimsel Arașturmalar Birimi'nin 0201701001 numaralı projesi olarak sürdürülmektedir. Türk-Amerikan Ilmi Araștırmalar Derneği, Turkish Cultural Foundation (TCF) ile birlikte, 2005 ylı "Doktora Üstü Araşurma Bursları" ndan birini vererek, çalıșmalarımı ikinci kez desteklemiştir. Malzemeyi değerlendirmeme izin veren Prof. Dr. Hayat Erkanal'a ve katkıda bulunan kuruluşlara içten teşekkürlerimi sunarım.

(t) Anastasio 1995, 203; Rova 2000, 241; 2003a, 3; Roaf ve Killick 2003, 80-81.

${ }^{7}$ Uysal baskuda.

8 Yöresel dilde Tell Minar Tılmınarê, Giremira ise Girêmira şeklinde yazılmaktadır.

${ }^{9}$ Parçaların renk tanımlarında Munsell Soil Color Charts (Baltimore 1975) kullamılmışur.

${ }^{10}$ Yayın hazırlıklan devam eden Girnavaz malzemesine ve basım așamasında olan Kertvin buluntularına, sayfa numaraları kesinlik kazanmadığı için auf yapılmamıștır. 
Malzemenin değerlendirmesine geçmeden önce, kendine özgü bir terminolojiye sahip olan Ninive 5 kültürünün kronolojisi üzerinde durmak gerekmektedir. Ninive 5 kültürü, kap formları ve bezeme tiplerinde görülen gelişmelere göre kendi içerisinde altı döneme ayrılmaktadır. Özellikle son yıllarda elde edilen veriler sayesinde, bu dönemlerin Güney Mezopotamya ve Suriye Cezire'si kronolojilerine göre hangi devirler arasında yer aldığı hemen hemen kesin olarak saptanmıştır ${ }^{11}$.

Kuzey Mezopotamya ve Kuzeydoğu Suriye'de, Uruk Devri yaklaşık yüz yıl daha uzun sürmüștür. Bu bölgelerde Son Uruk (Terminal Uruk) döneminden sonra ortaya çıkan Ninive 5 kültürünün ilk safhası, Cemdet Nasr Devri'nin sonları ile I. Erken Hanedanlar Devri'nin başları arasında yer aldığı kabul edilen Geçiş dönemidir. Boya bezemeli seramiğin ilk örneklerinin görüldüğü bu dönemde, çizi bezemeli seramik yoktur. Sonraki safha, I. Erken Hanedanlar Devri'nin başları ile paralel olduğu anlașlan Ara dönemdir. Boya bezemeli seramiğin gelișimini sürdürdüğü bu dönemde, çizi bezemeli ilk örneklerin de ortaya çıktığı düşünülmektedir. Suriye Cezire'si kronolojisine göre, Geçiş dönemi ve Ara dönem Erken Cezire 0 safhası içinde yer almaktadır.

Boya ve Erken Çizi Bezeme dönemi, I. Erken Hanedanlar Devri'nin büyük bir kısmını kapsamaktadır. Boya bezemeli seramiğin en olgun evresi olan bu safhada, çizi bezemeli seramik de belirgin bir şekilde görülmektedir. Bunu takip eden Çizi ve Oyma Bezeme döneminin, I. Erken Hanedanlar Devri'nin sonlan ile II. Erken Hanedanlar Devri'nin başları arasında yer aldığı düșünülmektedir. Bu dönemde boya bezemeli seramik devam etmekle birlikte sayısal olarak azalmıștır. Diğer grupta ise çizi bezeme ile birlikte, oyma bezeme başta olmak üzere daha derin süsleme teknikleri de ortaya çıkmıștır. Suriye Cezire'si kronolojisine göre, Boya ve Erken Çizi Bezeme dönemi ile Çizi ve Oyma Bezeme dönemi Erken Cezire I safhası içindedir.

Boya bezemeli seramiğin bulunmadığı Geç Oyma Bezeme dönemi, II. Erken Hanedanlar Devri'nin sonları ile IIIa evresinin bașları arasma yerleştirilmektedir. Suriye Cezire'si kronolojisine göre, Erken Cezire II ev-

11 Ninive 5 seramiğinde saptanan dōnemlerin adlandırılması ve tarihlendirilmeleri konusunda, yapılan son çalışmalar olan Lebau 2000 ve Rova 2003a esas alınmış, daha önce yapılan değerlendirmeler buna göre uyarlanmıștr. 
resi içindedir. Son safha olan Post Ninive 5 dönemi ise Erken Hanedanlar IIIa evresinin başlarından itibaren gelişim göstermektedir. Suriye Cezire'si kronolojisine göre, dönemin bașlangıcı Erken Cezire IIIa evresinin başlarma verilmektedir.

Giremira'dan bulunan 3 örnekle temsil edilen çanak formundaki parçalar iki ayrı tiptedir. İlk tip, hafif içe eğik dik duruşlu, basit ağız kenarlı ve dışbükey gövdelidir (Levha 1, 1-2). Yuvarlak, yuvarlatılmıș düz ya da düz dipli olan benzerleri Tepe Gawra ${ }^{12}$, Tell Brak ${ }^{13}$, Chagar Bazar ${ }^{14}$, Girharrin $^{15}$ ve Tell Leilan'dan ${ }^{16 i}$ ele geçmiştir.

İkinci çanak tipi ise hafif içe eğik dik duruşlu, dışa kalınlaştırılmış ağız kenarlı ve dışbükey gövdelidir (Levha 1,3). Düz dipli olan benzerleri Ninive ${ }^{17}$, Tell Karrana $3^{18}$, Tepe Gawra ${ }^{1 !}$, Tell Leilan ${ }^{20}$, Tell Durdara ${ }^{21}$, Tall al-Raqa'i ${ }^{22}$, Tell Jigan' ${ }^{23}$, Tell Brak ${ }^{2-1}$, Girharrin' ${ }^{25}$, Tell Barri ${ }^{26}$, Tell Fisna ${ }^{27}$, Tell Jessary ${ }^{28}$ ve Chagar Bazar'dan"2! bulunmuştur.

12 Speiser 1935, Lev. LXIII, 22. Geçiş dōnemi ya da Ara dönem; Mallowan 1947, Lev. LXXIV, 11. Çizi ve Oyma Bezeme dönemi; Matthews 1995, Șek. 18, 2. Geç Oyma Bezeme dōnemi; Oates 1982, Şek. 2, 29. Post Ninive 5 dönemi.

${ }^{13}$ Mallowan 1947, Lev. LXXIV, 11. Çizi ve Oyma Bezeme dönemi; Matthews 1995, \$ek. 18, 2. Geç Oyma Bezeme dỏnemi; Oates 1982, Sek. 2, 29, 31, 34-35; Matthews 1995, Sek. 17, 9 . Post Ninive 5 dönemi; Mallowan 1947, Lev. LXXIV, 14-15. Akkad Devri.

"I Mallowan 1936, Sek. 9, 2. Geç Oyma Bezeme dönemi.

15 Ay 1995, Sek. IV, 1. Geç Oyma Bezeme dōnemi.

${ }^{16}$ Scwartz 1988, Sek. 28, 6; Weiss 1990, Sek. 14, 1-2, 9. Akkad Devri.

17 Campbell-Thompson ve Mallowan 1933, Lev. LVI, 6; LXI, 2; Gut 1995, Lev. 72, 1104. 1107-1108. Ara dōnem; Lev. 95, 1339. Geç Oyma Bezeme dōnemi

${ }^{14}$ Rova 2003b, Sekk. 4, 7. Geçiș Dönemi; 1993, Lev. XXXII, 355. Ara dōnem.

1:! Speiser 1935, Lev. LXV, 53. Boya ve Erken Çizi Bezeme dōnemi. VII. tabaka.

20) Schwartz 1988, Şek. 50, 2. Boya ve Erken Çizi Bezeme dönemi. IIIa tabakası; Mayo ve Weiss 2003, Şek. 7, 1. Boya ve Erken Çizi Bezeme dōnemi. IIIb tabakası; Calderone ve Weiss 2003. Șek. 7, 5. Geç Oyma Bezeme dönemi. IIId tabakası.

${ }^{21}$ Spanos 1988, Şek. 11, 3. Boya ve Erken Çizi Bezeme dönemi ya da Çizi ve Oyma Bezeme dỏnemi. I. alan.

${ }^{22}$ Curvers ve Schwartz 1990, Sek. 25, 4. Cizi ve Oyma Bezeme dönemi. 4. tabaka; Șek. 20, 13. 16-17, 20. Geç Oyma Bezeme dónemi. 3. tabaka; Șek. 7, 14. Post Ninive 5 dönemi ve Akkad Devri'nin bașları. 2. tabaka

${ }^{23}$ Ii ve Kawamata 1984-85, Şek. 31, 9; Fujii et. al. 1987, Şek. 6, 50. Geç Oyma Bezeme dōnemi. B alam

${ }^{21}$ Oates 1986, Sek. 5, 91. olasılıkla Geç Oyma Bezeme dönemi.

${ }^{25}$ Ay 1995, Șek. IV, 10. Geç Oyma Bezeme dönemi.

2ti Biscione 1982, no. 1-2, 20, 22, 36. Olasılıkla Geç Oyma Bezeme dönemi. 3-1. tabakalar.

${ }^{27}$ Numoto 1988, Sek. 21, 137. Post Ninive 5 dönemi ve Akkad Devri. Vb tabakası.

${ }^{28}$ Numoto 1990, Sek. 8, 129. Post Ninive 5 dōnemi ve Akkad Devri. A alam, 2 b tabakası.

${ }^{29}$ Mallowan 1936, Sek. 9, 4. Akkad Devri. 23 numaralı mezar. 
Tell Minar'dan 5 ve Giremira'dan 6 örneği bulunan bardak formundaki 11 parça, beş ayrı tiptedir. Bunlardan dik duruşlu, basit ağız kenarlı ve düz gövdeli olan ilk tipin örneği Giremira'dan ele geçmiștir (Levha 1, 4). Yuvarlak ya da düz dipli olan benzerleri Tell Brak ${ }^{30}$ ve Tell Leilan'dan ${ }^{31}$ bulunmuştur.

Tell Minar'dan ele geçen 2 örneği bulunan bardakların ikinci tipi, hafif içe eğik dik duruşlu, basit ağız kenarlı ve dışbükey gövdelidir (Levha 1, 5-6; Resim 5, 1). İlk parçanın bezemesiz olmasına karşılık, diğer parça Geç Oyma Bezeme döneminin karakteristik bir kompozisyonu ile süslenmiștir. Söz konusu süsleme, birbirlerinin ara boşluklarına gelecek şekilde iki sıra halinde yapılmış, aralanı sık dikey çizgilerle taralı kısa ve dolgun oyma bezeme motiflerinden oluşmaktadır ${ }^{32}$. Sivri dipli olan benzerleri Tell Karana $3^{33}$, Tell Leilan ${ }^{34}$, Chagar Bazar ${ }^{35}$, Tell Mohammed "Arab ${ }^{36}$, Tell Jigan ${ }^{37}$ ve Tall al-Raqa'i'den ${ }^{38}$ ele geçmiştir.

Tell Minar'dan 2 ve Giremira'dan 1 parça ile temsil edilen üçüncü bardak tipi, dik duruşlu, basit ağız kenarlı ve dışbükey gövdelidir (Levha 1, 7-9; Resim 5, 2-3). Her iki merkezden de birer örnek çizi-oyma bezemelidir. Bunlardan Giremira örneğindeki bezeme, Ninive 5 seramiğinde nadir görülen bir motiftir. Söz konusu motif, üstte ve altta iki sıra halinde işlenmiş yatay yivlerin arasında yer alan, birbirini takip eden geniş açı sıralarının içinde iki sıra sağa dönük diyagonal tarama şeklindedir (Levha 1, 8; Resim 5, 2). Motifin çok daha düzensiz yapılmış bir benzeri, Boya ve

${ }^{30}$ Oates 1982, Şek. 4, 53. Post Ninive 5 dönemi.

${ }^{31}$ Schwartz 1988, Sek. 28, 8; Weiss 1990, Sek. 14, 8, 12. Akkad Devri. Ilb tabakast.

${ }^{32}$ Numoto $1993,85,87$, Sek. 4, 158.

${ }^{33}$ Rova 2003b, Șek. 6, 2-3. Olasılıkla Boya ve Erken Çizi Bezeme Dönemi.

${ }^{34}$ Schwartz 1988, Sek. 47, 5. Boya ve Erken Çizi Bezeme dönemi. Illa tabakası; Șek. 42, 1. Çizi ve Oyma Bezeme dönemi ya da Geç Oyma Bezeme dönemi. IIIb tabakası; Şek. 31, 9; 33, 8. Geç Oyma Bezeme dönemi. IIId tabakası.

${ }^{35}$ Mallowan 1947, Lev. LXXXII, 3. Boya ve Erken Çizi Bezeme dönemi ya da Çizi ve Oyma Bezeme dōnemi. 215 numaralı mezar; Mallowan 1936. Șek. 18, 8. Post Ninive 5 döneminin sonları ya da Akkad Devri. 4-3. tabakalar; Sek. 10, 5-6. Akkad Devri. 3. tabaka, 58 ve 28 numaralı mezarlar; Şek. 18, 6. Akkad Devri. 2. tabaka.

${ }^{36}$ Roaf 1983, Şek. 4, 09. Boya ve Erken Çizi Bezeme dōnemi ya da Geç Oyma Bezeme dönemi. 23 numaralı mezar.

${ }^{37}$ Numoto 1992, Şek. 6, 61. Boya ve Erken Çizi Bezeme dönemi ya da Geç Oyma Bezeme dönemi. C alam.

${ }^{38}$ Curvers ve Schwartz 1990, Șek. 20, 4-6; 21, 1-2. Geç Oyma Bezeme dōnemi. 3. tabaka. 
Erken Çizi Bezeme döneminde Tell Leilan'dan tanınmaktadır ${ }^{39}$. Tell Minar örneğindeki bezeme ise araları sık yatay çiziler ile taralı, sola dönük çift kıvrımlı açı sıraları oluşturan yivlerden meydana gelmektedir (Levha 1, 9; Resim 5, 3). Bu kompozisyonun dikey yiv sıraları ile birlikte uygulanmış benzerleri, Geç Oyma bezeme döneminde görülmektedir ${ }^{40}$. Yuvarlak dipli olan benzerleri Tell Kutan ${ }^{41}$, Tell Karrana $3^{42}$, Tell Leilan ${ }^{43}$, Tall alRaqa'i ${ }^{44}$, Tell Mohammed 'Arab ${ }^{45}$, Chagar Bazar ${ }^{46}$, Tell Brak ${ }^{47}$, Tell Jigan ${ }^{18}$, Tell Gabi West ${ }^{49}$, Tall al-Hamidiya ${ }^{50}$ ve Tell Germayir'den ${ }^{51}$ bulunmuștur.

Giremira'dan 1 örneği bulunan dördüncü bardak tipi, dıșa kalınlaștırılmış ağız kenarlı, dik duruşlu ve dışbükey gövdelidir (Levha 2, 10). Sivri dipli olan benzerleri Tell Fisna ${ }^{52}$, Tell Kutan ${ }^{53}$, Tell Brak ${ }^{54}$, Tell Leilan ${ }^{55}$,

${ }^{39}$ Schwartz 1988, Şek. 48, 7. IIIa tabakası.

${ }^{40}$ Numoto $1993,85,87$, Șek. 4, 169.

${ }^{41}$ Bachelot 1987, Şek. 9, ortada sağda. Geçiş dönemi, Ara dönem ya da Boya ve Erken Çizi Bezeme dönemi.

42 Rova 1991, Şek. A, 11-12. Geçiş dönemi, Ara dönem ya da Boya ve Erken Çizi Bezeme dönemi.

${ }^{43}$ Schwartz 1988, Șek. 51, 4. Boya ve Erken Çizi Bezeme dönemi. IIIa tabakası; Sek. 31, 4, 11, 14; 33, 7. Geç Oyma Bezeme dönemi. IIId tabakası.

${ }^{14}$ Curvers ve Schwartz 1990. Şek. 24, 15. Boya ve Erken Çizi Bezeme dönemi. 5. tabaka; Schwartz ve Curvers 1992, Şek. 7, 9. Post Ninive 5 dönemi ve Akkad Devri'nin bașları. 2. tabaka.

${ }^{15}$ Roaf 1983, Şek. 4, 02. Olasılıkla Boya ve Erken Çizi Bezeme dōnemi.

Hi Mallowan 1947, Lev. LXXXII, 11. Boya ve Erken Çizi Bezeme dõnemi ya da Geç Oyma Bezeme dōnemi. 211 numaralı mezar; Mallowan 1936, Şek. 10, 2. Akkad Devri. 2. tabaka, 24 numaralı mezar; Sek, 10, 8. Akkad Devri. 2. tabaka, 25 numaralı mezar; Şek. 20, 2. Akkad Devri. 3. tabaka, 26 numaralı mezar; Sek. 10, 1,3. Akkad Devri. 3. tabaka, 66 numaralı mezar.

${ }^{47}$ Mallowan 1947, Lev, LXXIV, 10. Boya ve Erken Çizi Bezeme dönemi, Çizi ve Oyma Bezeme dōnemi ya da Geç Oyma Bezeme dōnemi; Matthews 1995, Şek. 18, 8. Geç Oyma Bezeme dönemi.

${ }^{48}$ Ii ve Kawamata 1984-85, Şek. 31, 6; Fujii et. al. 1987, Şek. 6, 47. Geç Oyma Bezeme dönemi.

${ }^{49}$ Künhe 1978-79, Şek. 15. Geç Oyma Bezeme dönemi.

5) Eichler 1990, Lev. 33, 2. Geç Oyma Bezeme dönemi.

${ }^{51}$ Mallowan 1937, Sek. 18, 14. Post Ninive 5 dönemi. 20 numaralı mezar.

52 Numoto 1988, Sek. 15, 15; 19, 96. Boya ve Erken Çizi Bezeme dönemi. 6. tabaka.

${ }^{53}$ Forest 1987, Șek. 9, solda üstten dördüncü. Boya ve Erken Cizi Bezeme dōnemi.

${ }^{54}$ Mathews et. al. 1994, Şek. 5, 8. Boya ve Erken Çizi Bezeme dōnemi; Oates 1986, Şek. 5, 99; Mathews 1995, Șek. 12, 7; 13, 1; 14, 3; 19, 2. Çizi ve Oyma Bezeme dōnemi; Oates 1986, Şek. $5,96$. Geç Oyma Bezeme dönemi.

${ }^{55}$ Schwartz. 1988, Şek. 47, 3; 48, 1, 5. Boya ve Erken Çizi Bezeme dōnemi. IIIa tabakası; Şek. 32, 1; 33, 5. Cizi ve Oyma Bezeme dōnemi. IIIc tabakası; Calderone ve Weiss 2003, Sek. 5, 4. Geç Oyma Bezeme dōnemi. IIId tabakası. 
Tell Billa ${ }^{56,}$, Chagar Bazar ${ }^{57}$, Ninive ${ }^{58}$, Tell Mohammed Arab ${ }^{50}$, Tell Barri ${ }^{60}$, Tall al-Hamidiya ${ }^{i 1}$ ve Tall al-Raqa'i'den ${ }^{62}$ bulunmuștur.

Giremira'dan 3 ve Tell Minar'dan 1 parça ile temsil edilen son bardak tipi, dışa kalıılaştırılmış ağız kenarlı ve dik duruşludur (Levha 2, 11-14; Resim 6, 4-5). Bu tür kaplarda, gövde kabın yarısı ya da alt kısmına yakın bir noktada keskinlik olușturduktan sonra, dibe doğru daralarak inmektedir. Her iki merkezden de birer parça bezemelidir. Cok küçük kısımları korunmuş bu parçalardaki bezeme, bardakların üçüncü tipi içinde yer alan bir örnekte üzerindeki motifin (Levha 1, 9; Resim 5, 3) dikey yiv sıraları ile birlikte uygulanmış şeklidir. Sivri, yuvarlak ya da düz dipli olan benzerleri Telul eth-Thalathat $V^{63}$, Chagar Bazar ${ }^{64}$, Tell Brak ${ }^{65}$, Tall al-

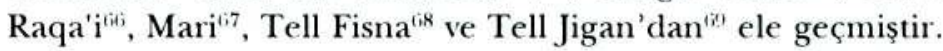

Tell Minar'dan bulunan 2 örnek ile temsil edilen çömlekler iki ayrı tiptedir. Bunlardan ilk tip dışa çekik aşağıya eğik ağız kenarlı, kısa boyunlu ve yuvarlak gövdelidir (Levha 2, 15). Formun sağlam örnekleri genellikle yuvarlak diplidir. Nadir olarak düz dipli kaplar da görülmektedir. Benzer-

\footnotetext{
${ }^{50}$ Speiser 1933, Lev. LII, 5. Boya ve Erken Çizi Bezeme dönemi ya da Geç Oyma Bezeme dönemi.

${ }^{57}$ Mallowan 1936, Șek. 10, 7. Boya ve Erken Çizi Bezeme dönemi ya da Geç Oyma Bezeme dönemi. 5. tabaka, 68 numarah mezar.

${ }^{58}$ Gut 1995, Lev. 93, 1306. Çizi ve Oyma Bezeme dönemi; Lev. 95, 1330. Geç Oyma Bezeme dönemi.

${ }^{51)}$ Killick 1986, Şek. 4, 1-2. Geç Oyma Bezeme dönemi. 3, tabaka.

${ }^{10}$ Biscione 1982, no. 8. Geç Oyma Bezeme dōnemi. 3-1. tabakalar.

${ }^{(i 1}$ Eichler et. al. 1990, Lev. 33, 6-12, 15, 19. Geç Oyma Bezeme dōnemi.

${ }^{62}$ Curvers ve Schwartz 1990, Sek. 20, 7; Fortin ve Schwartz 2003, Sek. 7, 4. Geç Oyma Bezeme dönemi. 3. tabaka.

${ }^{13}$ Fukai et. al. 1974, Lev: XLVII, 2. Boya ve Erken Çizi Bezeme dönemi.

${ }^{t i 1}$ Mallowan 1936, Şek. 18, 1-4, 7. Boya ve Erken Çizi Bezeme dönemi. 5. tabaka, 67 ve 68 numaralı mezarlar.

${ }^{105}$ Mathews 1995, Sek. 12, 8; 20, 3. Cizi ve Oyma Bezeme dönemi; Oates 1986. Sek. 5, 85-86. Olasılıkla Geç Oyma Bezeme dönemi.

(ki) Fortin ve Schwartz 2003, Sek. 7, 8. Geç Oyma Bezeme dönemi. 3. tabaka.

${ }^{67} 7$ Parrot 1954, Șek. 7. Geç Oyma Bezeme dönemi.

${ }^{\text {(ix }}$ Nomoto 1988, Şek. 41, 2-4. Post Ninive 5 dönemi. 1 numaralı mezar; Șek. 22, 126, 151. Post Ninive 5 donnemi ya da Akkad Devri. Vb ve Va tabakaları.

(4:) Ii ve Kawamata 1984-85, Sek. 20, 1; Fujii et. al. 1987, Sek. 6, 63. Akkad Derri. B alanı, 4 numaralı mezar.
} 
leri Chagar Bazar $^{70}$, Tall al-Hamidiya ${ }^{71}$, Tall al-Raqa'i ${ }^{72}$ ve Tell Fisna'dan ${ }^{73}$ bulunmuştur.

İkinci çömlek tipi ise dışa çekik uzatılmış ağız kenarlı, kısa boyunlu ve yuvarlak gövdelidir. Boynun gövde ile birleştiği kısımda bir keskinlik söz konusudur (Levha 2, 16; Resim 6, 6). Kabın gövdesi sık olarak işlenmiş dikey çizi taramalarla bezenmiştir. Bu basit bezeme şeklinin benzerleri, daha çok Geç Oyma Bezeme döneminden tanınmaktadır ${ }^{74}$. Yuvarlak dipli olan bir benzeri Tell Brak'dan ele geçmiştir ${ }^{75}$.

Dip parçaları sivri, yuvarlak, düz ve pedestal olmak üzere dört ayrı tiptedir. Bardak türü kaplarda karşımıza çıkan sivri dip parçaları, her iki merkezde de çok sayıdadır (Levha 2, 17-18). Giremira'dan bulunan yuvarlak dip parçası (Levha 2, 19), Ninive 5 seramiğindeki bütün kap tiplerinde görülebilmektedir. Tell Minar'dan ele geçen küçük düz dip parçası, çanak ve bardak türü kaplarda kullanılan bir dip şeklidir (Levha 2, 20). Giremira'dan bulunan son 2 dip parçası ise pedestal dip örnekleridir (Levha 2, 21-22). Bu dip biçimi de, Ninive 5 seramiğinde yaygın olarak bulunan ayaklı kadeh formundaki kaplarda görülmektedir.

Bunların dışında 2 gövde parçası da bezemeli olmaları bakımından önem tașımaktadır. Giremira'dan bulunan ilk örnekte, bezeme kompozisyonunun çok küçük bir kısmı korunmuştur (Levha 2, 23; Resim 6, 7). Bezeme dış kenarları diyagonal sık çiziler ile taralı, aşağıya dönük açı olușturan iki yivden meydana gelmektedir. Bu tür bezemeye sahip bir örnek Tell Barri'den tanınmakta ve Geç Oyma Bezeme dönemine tarihlendirilmektedir ${ }^{7 i}$. Söz konusu örnekteki kompozisyon, araları diyagonal sık çiziler ile taralı, iç içe iki sıra halinde yapılmış, aşağıya ve yukarıya dönük açı oluşturan devamlı yivlerden meydana gelmektedir. Ayrıca, tam

${ }^{70}$ Mallowan 1947, Lev. LXXXII, 2. Olasılıkla Geç Oyma Bezeme dōnemi; Mallowan 1936, Sek. 20, 12. Akkad Devri. 2-3. tabakalar; Sek. 12, 6; 20, 1 Akkad Devri. 3. tabaka, 28 numarah mezar.

${ }^{71}$ Eichler at. al. 1990, Lev. 33, 21. Geç Oyma Bezeme dönemi.

72 Curvers ve Schwartz 1990. Șek. 20, 23, 27. Geç Oyma Bezeme dönemi. 3. tabaka.

${ }^{73}$ Numoto 1988, Sek. 43, 22. Post Ninive 5 dönemi.

${ }^{74}$ Rova 1988, 105, 108-109, ek IV, 35a, Lev. VI.

75 Mallowan 1947, Lev. LXXV, 12. Akkad Devri.

${ }^{75}$ Biscione 1982, no. 7. 3-1. tabakalar 
aymı olmamakla birlikte, benzer anlayışta yapılmıs bir örnek de Tell Leilan'dan bilinmekte, Çizi ve Oyma Bezeme dönemine verilmektedir ${ }^{77}$.

Tell Minar'dan bulunan diğer parça da oldukça küçüktür (Levha 2, 24 ; Resim 6,8 ). Örnekte sola dönük yivlerden oluşan üçlü bir açı sırasının bulunduğu görülmekte, bir başka sıranın varlığı da anlaşılmaktadır. Bu bezemenin en yakın benzeri, dikey yiv sıraları ile birlikte işlenmiş sağa dönük ikili açı sırası oluşturan yivlerden meydana gelen bir biçimdedir. Söz konusu kompozisyon, Geç Oyma Bezeme döneminden tanınmaktadir ${ }^{78}$.

Bu iki merkezden ele geçen Ninive 5 seramiği parçaları, özellikle bezemeli örneklerin ortaya koyduğu tarihlendirme kriterlerine göre değerlendirildiğinde, Giremira'da Boya ve Erken Çizi Bezeme döneminin varlığı söz konusu olabilir (Levha 1, 8; Resim 5, 2). Çizi ve Oyma Bezeme dönemini ortaya koyan geçerli bir veri elde edilememiştir. Bu dönemler Girnavaz ve Kertvin'den tanınmaktadır. Hem Tell Minar hem de Giremira' da Geç Oyma Bezeme döneminin varlığı belirgindir (Levha 1, 6, 9; 2, 11$12,16$; Resim $5,1,3 ; 6,4-8)$. Post Ninive 5 dönemi de büyük bir olasılıkla vardir.

Tell Minar ve Giremira, hemen yakınlarında yer alan Girnavaz ve Kertvin ile birlikte, Kuzey Mezopotamya ve Kuzeydoğu Suriye'den tanınan Ninive 5 kültürünün Nusaybin Bölgesi'ndeki uzantılarıdır. Eldeki veriler, Nusaybin ilçesinin Ninive 5 kültürü'nün gerçek anlamda yayıldığı bir alan olduğunu göstermektedir. Bölgede yapılacak yüzey araşturmaları, çok sayıda yeni merkezin tanınmasımı sağlayacaktır.

${ }_{78}^{77}$ Schwartz 1988, Şek. 39, \$, IIIb tabakası (?); Numoto 1993, 79, Sek. 2, 73.

${ }^{78}$ Numoto 1993, 85, 87, Sek. 4, 166. 


\section{Katalog}

Levha no:

1,1

Hamur rengi: $\quad 5$ Y $8 / 3$

Merkez:

Giremira

Dış astar rengi: $\quad 5$ Y $8 / 2$

Ağız çapı:

$15 \mathrm{~cm}$

İç astar rengi: $\quad 5$ Y $8 / 2$

Levha no:

1,2

Hamur rengi: $\quad 5$ Y $8 / 3$

Merkez:

Giremira

Ağız çapı:

$16 \mathrm{~cm}$

Dış astar rengi: $\quad 5$ Y $8 / 2$

İç astar rengi: $\quad 5$ Y $8 / 2$

Levha no:

1,3

Hamur rengi: $\quad 2.5 \mathrm{Y} 8 / 2$

Merkez:

Tell Minar

Ağız çapı:

$16 \mathrm{~cm}$

Dış astar rengi: $\quad 5$ Y $8 / 2$

İç astar rengi: $\quad 5$ Y $8 / 2$

Levha no:

1,4

Hamur rengi: $\quad 5$ Y $8 / 4$

Merkez:

Giremira

Dış astar rengi: 5 Y $8 / 4$

Ağız çapı:

$6 \mathrm{~cm}$

İç astar rengi: $\quad 5$ Y $8 / 4$

Levha no:

1,5

Merkez:

Tell Minar

Ağız çapı:

$7 \mathrm{~cm}$

Hamur rengi: $\quad 5$ Y $8 / 2$

Dış astar rengi: 5 Y $8 / 2$

İç astar rengi: $\quad 5$ Y $8 / 2$

Levha no:

1,6

Hamur rengi: $\quad 5 \mathrm{Y} 8 / 2$

Merkez:

Tell Minar

Ağız çapı:

$10 \mathrm{~cm}$

Dış astar rengi: $\quad 5$ Y $8 / 2$

İç astar rengi: $\quad 5$ Y $8 / 2$

Levha no:

1,7

Hamur rengi: $\quad 5 \mathrm{Y} 8 / 2$

Merkez:

Tell Minar

Ağız çapı:

$8 \mathrm{~cm}$

Dış astar rengi: $\quad 5$ Y $8 / 2$

İç astar rengi: $\quad 5$ Y $8 / 2$

Levha no:

1,8

Hamur rengi: $\quad 2.5$ Y $8 / 2$

Merkez:

Giremira

Dış astar rengi: 2.5 Y $8 / 2$

Ağız çapı:

$8 \mathrm{~cm}$

İç astar rengi: $\quad 10 \mathrm{YR} 8 / 3$ 


\begin{tabular}{|c|c|c|c|}
\hline Levha no: & 1,9 & Hamur rengi: & $2.5 \times 8 / 2$ \\
\hline Merkez: & Tell Minar & Dış astar rengi: & $5 \times 8 / 3$ \\
\hline Ağız çapı: & $10 \mathrm{~cm}$ & İç astar rengi: & $5 \times 8 / 3$ \\
\hline Levha no: & 2,10 & Hamur rengi: & $5 \mathrm{Y} 8 / 2$ \\
\hline Merkez: & Giremira & Dıș astar rengi: & $5 Y 8 / 1$ \\
\hline Ağız çapı: & $8 \mathrm{~cm}$ & İç astar rengi: & $5 Y 8 / 1$ \\
\hline Levha no: & 2,11 & Hamur rengi: & $5 \mathrm{Y} 8 / 2$ \\
\hline Merkez: & Giremira & Dıș astar rengi: & $5 \mathrm{Y} 8 / 2$ \\
\hline Ağız çapı: & $8 \mathrm{~cm}$ & İç astar rengi: & $5 \times 8 / 2$ \\
\hline Levha no: & 2,12 & Hamur rengi: & $5 \times 7 / 3$ \\
\hline Merkez: & Giremira & Dıș astar rengi: & $5 \times 7 / 2$ \\
\hline Ağız çapı: & $12 \mathrm{~cm}$ & İç astar rengi: & $5 \times 7 / 2$ \\
\hline Levha no: & 2,13 & Hamur rengi: & $5 \times 8 / 2$ \\
\hline Merkez: & Tell Minar & Dıș astar rengi: & $5 Y 8 / 2$ \\
\hline Ağız çapı: & $10 \mathrm{~cm}$ & İç astar rengi: & 5 Y $8 / 2$ \\
\hline Levha no: & 2,14 & Hamur rengi: & 5 Y $8 / 2$ \\
\hline Merkez: & Giremira & Dış astar rengi: & $5 \times 8 / 1$ \\
\hline Ağız çapı: & $12 \mathrm{~cm}$ & İç astar rengi: & $5 Y 8 / 1$ \\
\hline Levha no: & 2,15 & Hamur rengi: & $5 Y 8 / 2$ \\
\hline Merkez: & Tell Minar & Diş astar rengi: & $5 \times 8 / 2$ \\
\hline Ağız çapı: & $8 \mathrm{~cm}$ & İç astar rengi: & $5 Y 8 / 2$ \\
\hline Levha no: & 2,16 & Hamur rengi: & $5 Y 8 / 2$ \\
\hline Merkez: & Tell Minar & Dış astar rengi: & $5 \mathrm{Y} 8 / 2$ \\
\hline Ağız çapı: & $8 \mathrm{~cm}$ & İç astar rengi: & $5 \mathrm{Y} 8 / 2$ \\
\hline Levha no: & 2,17 & Hamur rengi: & 2.5 Y $8 / 2$ \\
\hline Merkez: & Tell Minar & $\begin{array}{l}\text { Diş astar rengi: } \\
\text { İç astar rengi: }\end{array}$ & $\begin{array}{l}2.5 \mathrm{Y} 8 / 2 \\
5 \mathrm{Y} 8 / 3\end{array}$ \\
\hline
\end{tabular}


Levha no:

Merkez:

Levha no:

Merkez:

Levha no:

Merkez:

Dip çapı:

Levha no:

Merkez:

Dip çapı:

Levha no:

Merkez:

Levha no:

Merkez:

Levha no:

Merkez:
2,18

Giremira

2, 19

Giremira

2,20

Tell Minar

$2 \mathrm{~cm}$

2, 21

Giremira

$5 \mathrm{~cm}$

2, 22

Giremira

2,23

Giremira

2, 24

Tell Minar
Hamur rengi: $\quad 5$ Y $8 / 3$

Dış astar rengi: 5 Y $8 / 2$

İç astar rengi: $\quad 5$ Y $8 / 2$

Hamur rengi: $\quad 2.5 \mathrm{Y} 8 / 2$

Diș astar rengi: 2.5 Y $8 / 2$

İç astar rengi: $\quad 2.5 \mathrm{Y} 8 / 2$

Hamur rengi: $\quad 5 \mathrm{Y} 8 / 3$

Dış astar rengi: $\quad 5$ Y $8 / 2$

İç astar rengi: $\quad 5 \mathrm{Y} 8 / 3$

Hamur rengi: $\quad 5$ Y $8 / 4$

Diș astar rengi: $\quad 5 \mathrm{Y} 7 / 4$

İç astar rengi: $\quad 5$ Y $7 / 4$

Hamur rengi: $\quad 5$ Y $8 / 1-10$ YR $8 / 3$

Dış astar rengi: 5 Y $8 / 1$

İç astar rengi: $\quad 10 \mathrm{YR} 8 / 3$

Hamur rengi: $\quad 5$ Y $7 / 2$

Dış astar rengi: $\quad 5$ Y $7 / 3$

İç astar rengi: $\quad 5 \mathrm{Y} 7 / 3$

Hamur rengi: $\quad 5 \mathrm{Y} 8 / 3$

Dış astar rengi: 5 Y $8 / 4$

İç astar rengi: $\quad 5$ Y $8 / 4$ 


\section{KAYNAKÇA}

Akyurt, İ. M., B. Devam, H. Erkanal ve A. T. Ökse. 1993. "1991 Girnavaz Kazıları." 14. Kazı Sonuçları Toplantısı 1: 267-280.

Anastasio, S. 1995. The Archaeology of Upper Mesopotamia. An Analytical Bibliography for the Pre-Classical Periods. Subartu 1. Tunhout: Brepols.

Ay, E. 1995. “Girharrin Höyüğü'nün Arkeolojik Değerlendirmesi." A. Erkanal, H. Erkanal, H. Hüryılmaz, A. T. Ökse, N. Çınardalı, S. Günel, H. Tekin, B. Uysal ve D. Yalçıklı (eds.), In Memoriam İ. Metin Akyurt Bahattin Devam Anı Kitabı. Eski Yakın Doğu Kültürleri Üzerinde İncelemeler. Studies for Ancient Near Eastern Cultures, 1332. İstanbul: Arkeoloji ve Sanat Yayıları.

Bachelot, L. 1987. "The French Archaeological Expedition to Saddam Dam the 2nd, Campaign at Kutan, May/June 1984." Research(e)s on the Antiquities of Saddam Dam Basin Salvage and Other Researches, 89-98. Baghdad: Republic of Iraq Ministry of Culture and Information, State Organization of Antiquities and Heritage Saddam Dam Basin Salvage Project.

Biscione, R. 1982. "La Ceramica del III Millennio." P. E. Pecorella ve M. Salvini (eds.), Tell Barri/Kahat 1. Relazione Preliminare SulleCampagne 1980 e 1981 a Tell Barri/Kahat, nel Bacino del Habur, 45-54. Roma: Consiglio Nationale Delle Ricerche Instituto Per Gli Studi Micenei ed Egeo-Anatolici.

Calderone, L. ve H. Weiss. 2003. "The End of the Ninevite 5 Period at Tell Leilan." H. Weiss ve E. Rova (eds.), The Origins of North Mesopotamian Civilization: Ninive 5 Chronology, Economy, Society, 193-220. Subartu 9. Turnhout: Brepols.

Campbell-Thompson, R. ve M. E. L. Mallowan. 1933. "The British Museum Excavations at Nineveh, 1931-32." Annals of Archaeology and Antropology 20: 71-186.

Curvers, H. H. ve G. M. Schwartz. 1990. "Excavations at Tell al-Raga'i: A Small Rural Site of Early Urban Northern Mesopotamia." American Journal of Archaeology 94/1: 3-23.

Devam, B. 1988. "Girnavaz Kazılarında Açığa Çıkarılan Ninive 5 Seramiğinin Önasya Arkeolojisindeki Yeri." Yüksek Lisans Tezi, Hacettepe Üniversitesi. 
Eichler, S., M. Wäfler ve D. Warburton. 1990. Tell al-Hamidiya 2, Vorbericht 1985-1987. Symposion Recent Excavations in the Upper Khabur Region. Orbis Biblicus et Orientalis, Series Archaeologica 6. Göttingen: Universitätsverlag Freiburg Schweiz Vandenhoeck \& Ruprecht Göttingen.

Erkanal, A. 1984. "Girnavaz Kazısının Anadolu Arkeolojisindeki Yeri ve Önemi." 1. Araştırma Sonuçlanı Toplantısı: 69-73.

Erkanal, A. ve H. Erkanal. 1989. "Archäologischer Überblick über die Provinz Mardin." K. Emre, M. Mellink, B. Hrouda ve N. Özgüç (eds.), Tahsin Özgüç'e Armağan. Anatolia and the Ancient Near East. Studies in Honor of Tahsin Özgüç, 129-134. Ankara: Türk Tarih Kurumu.

Erkanal, H. 1984. "1982 Girnavaz Kazıları." 5. Kazı Sonuçları Toplantısı: $131-135$.

Erkanal, H. 1985. "1983 Girnavaz Kazıları." 6. Kazı Sonuçları Toplantısı: 121-135.

Erkanal, H. 1986. "1984 Girnavaz Kazıları." 7. Kazı Sonuçları Toplantısı: 201-210.

Erkanal, H. 1988a. "1986 Girnavaz Kazısı." 9. Kazı Sonuçlanı Toplantısı 1: 361-365.

Erkanal, H. 1988b. "Girnavaz." Mitteilungen der Deutschen Orient Gesellschaft 120: 139-152.

Erkanal, H. 1989. "Mardin." Reallexikon der Assyriologie und Vorderasiatischen Archäologie 7. 5./6. Lieferung: 558-559.

Erkanal, H. 1990. "1988 Girnavaz Kazılanı." 11. Kazı Sonuçlanı Toplantısı 1: 261-273.

Erkanal, H. 1991a. "1988 Girnavaz Kazıları." Höyük 1: 29-36.

Erkanal, H. 1991b. "1989 Girnavaz Kazıları." 12. Kazı Sonuçları Toplantısı 1: 277-292.

Erkanal, H. 1998. "Girnavaz." 34. Uluslararası Assiriyoloji Kongresi: 171178. Ankara: Türk Tarih Kurumu.

Erkanal, H. 2000. "Mardin Bölgesi Arkeoloji Araștırmaları." GAP Bölgesi'nde Kültür Varlıklarının Korunması, Yaşatılması ve Tanıtılması Sempozyumu, 16-34. (01-05 Haziran 1998, Şanlıurfa). GAP Yayınları Kültür Dizisi 3. Ankara: T.C. Kültür Bakanlığı. 
Forest, J.-D. 1987. "Khirbet Derak and Kutan: A Preliminary Report of the French Excavations in the Saddam Dam Area (1983-1984)." Research(e)s on the Antiquities of Saddam Dam Basin Salvage and Other Researches, 82-8. Baghdad: Republic of Iraq Ministry of Culture and Information, State Organization of Antiquities and Heritage Saddam Dam Basin Salvage Project.

Fortin, M. ve G. M. Schwartz. 2003. "The Middle Habur in the Third Millennium B.C." H. Weiss ve E. Rova (eds.), The Origins of North Mesopotamian Civilization: Ninive 5 Chronology, Economy, Society, 221-248. Subartu 9. Turnhout: Brepols.

Fujii, H., H. İ, W. Kawamata, K. Matsumoto, H. Oguchi, K. Yaggi ve H. Numoto. 1987. "Working Report on First Season of Japanese Archaeological Excavation in Saddam Dam Salvage." Research(e)s on the Antiquities of Saddam Dam Basin Salvage and Other Researches, 33-61. Baghdad: Republic of Iraq Ministry of Culture and Information, State Organization of Antiquities and Heritage Saddam Dam Basin Salvage Project.

Fukai, S., K. Horiuchi ve T. Matsutani. 1974. Telul eth-Thalathat III. The Excavations of Tell V, The Fourth Season (1965). The Tokyo University Iraq-Iran Expedition Report 15. Tokyo: Tokyo University Press.

Gut, R. V. 1995. Das Prähistorische Ninive: Zur relativen Chronologie der frühen Perioden Nordmesopotamiens. Baghdader Forschungen 19. Mainz: Verlag Philipp von Zabern.

Ii, H. ve M. Kawamata. 1984-85. "The Excavations at Tell Jigan by the Japanese Archaeological Expedition: A Preliminary Report on the First Season of Work." (Japonca). al-Rafidan 5-6: 151-214.

Killick, R. 1986. "The Eski Mosul Region." U. Finkbeiner ve W. Röllig (eds.), Gamdat Nasr. Period or Regional Style? 229-244. Tübinger Atlas des Vorderen Orients 62. Wiesbaden: Dr. Ludwig Reichert Verlag.

Kühne, H. 1978-79. "Ausgrabungen und Forschungsreisen. Ausgrabungstätigkeit in Syrien." Archiv für Orientforschung 26: 145-180.

Lebau, M. 2000. "Stratified Archaeological Evidence and Compared Periodizations in the Syrian Jezirah During the Third Millennium B.C." C. Marro ve H. Hauptmann (eds.), Chronologies des Pays du Caucase et de l'Euphrate aux $I V^{\prime}-I I I^{\prime}$ millénaires, 167-192. Varia 
Anatolica 11. Institut Français d'Etudes Anatoliennes d'Istanbul. Paris: De Boccard.

Mallowan, M. E. L. 1936. "The Excavations at Tall Chagar Bazar and an Archaeological Survey of the Habur Region, 1934-35." Iraq 3: 1-86.

Mallowan, M. E. L. 1947. "Excavations at Tell Brak and Chagar Bazar." Iraq 9: 1-259.

Mallowan, M. E. L. 1964. "Ninevite 5.” K. Bittel, E. Heinrich, B. Hrouda ve W. Nagel (eds.), Vorderasiatische Archälogie, Studien und Aufsätze. Festschrift A. Moortgat, 142-154. Berlin: Verlag Gebr. Mann.

Matthews, R. J. 1995. "Excavations at Tell Brak, 1995." Iraq 57: 87-111.

Matthews, R. J., M. Matthews ve H. McDonald. 1994. "Excavations at Tell Brak, 1994." Iraq 56: 177-194.

Mayo, D. ve H. Weiss. 2003. "The Begimning of the Ninevite 5 Sequence at Tell Leilan." H. Weiss ve E. Rova (eds.), The Origins of North Mesopotamian Civilization: Ninive 5 Chronology, Economy, Society, 25-41. Subartu 9. Turnhout: Brepols.

McMahon, A. 1998. "The Kuyunjik Gully Sounding, Nineveh, 1989 \& 1990 Seasons." al-Rafidan 19: 1-32.

Numoto, H. 1988. "Excavations at Tell Fisna." (Japonca). al-Rafîdan 9: 172.

Numoto, H. 1990. "Findings from Tell Jessary." al-Rafidan 11: 201-236.

Numoto, H. 1991. "Painted Designs of the Ninevite 5 Pottery." al-Rafídan 12: $85-155$.

Numoto, H. 1992. "Ninevite 5 Pottery from Tell Jigan Area C." al-Rafídan 13: $139-158$.

Numoto, H. 1993. "Incised and Excised Designs of Ninevite 5 Pottery." alRafidan 14: 69-108.

Numoto, H. 1998. "Late Uruk and the Transitional Ninevite 5 Pottery from Tall Thalathat No. 5." al-Rafidan 19: 53-73.

Oates, J. 1982. "Some Late Early Dynastic III Pottery from Tell Brak." Iraq 44: $205-220$.

Oates, J. 1986. "Tell Brak: The Uruk/Early Dynastic Sequence." U. Finkbeiner ve W. Röllig (eds.), Gamdat Nasr. Period or Regional Style? 245-273. Tübinger Atlas des Vorderen Orients 62. Wiesbaden: Dr. Ludwig Reichert Verlag.

Parrot, A. 1954. "Les fouilles de Mari, neuvième campagne (Automne 1953)." Syria 31: 151-171. 
Roaf, M. 1983. "A Report on the Work of the British Archaeological Expedition in the Eski Mosul Dam Salvage Project." Sumer 39: 68-94.

Roaf, M. ve R. Killick. 1987. "A Mysterious Affair of Styles: The Ninevite 5 Pottery of Mesopotamia." Iraq 49: 199-230.

Roaf, M. ve R. Killick. 2003. "The Relative Chronology of Ninevite 5 Sites in the Tigris Region and Beyond." H. Weiss ve E. Rova (eds.), The Origins of North Mesopotamian Civilization: Ninive 5 Chronology, Economy, Society, 73-82. Subartu 9. Turnhout: Brepols.

Rova, E. 1988. Distribution and Chronology of Nineveh 5 Pottery and Its Culture. Contributi e Materiali di Archeologia Orientale II. Roma: Università Degli Studi di Roma, (La Sapienza).

Rova, E. 1991. "Pottery from Tell Karrana." Mesopotamia 26: 15-22.

Rova, E. 2000. "Early Third Millennium B.C. Painted Pottery Traditions in the Jezirah." C. Marro ve H. Hauptmann (eds.), Chronologies des Pays du Caucase et de I'Euphrate aux IVe-III' millénaires, 231-253. Varia Anatolica 11. Institut Français d'Etudes Anatoliennes d'Istanbul. Paris: De Boccard.

Rova, E. 2003a. "Ninevite 5 Relative Chronology, Periodization and Distribution: An Introduction." H. Weiss ve E. Rova (eds.), The Origins of North Mesopotamian Civilization: Ninevite 5 Chronology, Economy, Society, 1-10. Subartu 9. Turnhout: Brepols.

Rova, E. 2003b. "Tell Karrana 3: Ceramic Evidence for Late Uruk/Ninevite 5 Transition." H. Weiss ve E. Rova (eds.), The Origins of North Mesopotamian Civilization: Ninive 5 Chronology, Economy, Society, 11-24. Subartu 9. Turnhout: Brepols.

Schwartz, G. M. 1985. "The Ninevite Period and Current Research." Paléorient 11/1: 53-69.

Schwartz, G. M. 1988. A Ceramic Chronology from Tell Leilan: Operation 1. H. Weiss (ed.). Yale Tell Leilan Research 1. New Haven, London: Yale University Press.

Schwartz, G. M. ve H. H. Curvers. 1992. "Tell al-Raga'i 1989 and 1990: Further Investigations at a Small Rural Site of Early Urban Northern Mesopotamia." American Journal of Archaeology 96/3: 397-419.

Spanos, P. Z. 1988. "Ausgrabungen in Tall Durdara (Eski-Mosul-Projekt) und Tall Hamad Aga as-Sagir (Gazira Projekt), Nordirak, 1986.” Mitteilungen der Deutschen Orient Gesellschaft 120: 59-92. 
Speiser, E. A. 1933. "The Pottery of Tell Billa." Museum Journal 23: 249308.

Speiser, E. A. 1935. Excavations at Tepe Gawra I, Levels I-VIII. American School of Oriental Research. Philadelphia: University of Pennsylvania Press.

Uysal, B. 1998. "Girnavaz Kazılarının Ișığı Altında Anadolu'da Ninive 5 Seramiği.” Doktora Tezi, Hacettepe Üniversitesi.

Uysal, B. (Baskıda). "Kertvin, Nusaybin Bölgesi'nde Bulunan Önemli Bir Ninive 5 Merkezi." A. Erkanal-Öktü, E. Özgen, S. Günel, A. T. Ökse, H. Hüryılmaz, H. Tekin, N. Çnardalı-Karaaslan, B. Uysal, F. A. Karaduman, A. Engin, R. Spiess, A. Aykurt, R. Tuncel, U. Deniz ve A. Rennie (eds.)., Hayat Erkanal'a Armağan, Kültürlerin Yansıması. Studies in Honor of Hayat Erkanal, Cultural Reflections. İstanbul: Homer Kitapevi.

Weiss, H. 1990. "Tell Leilan 1989: New Data for Mid-Third Millennium Urbanization and State Formation." Mitteilungen der Deutschen Orient Gesellschaft 122: 193-218. 
Bora Uysal

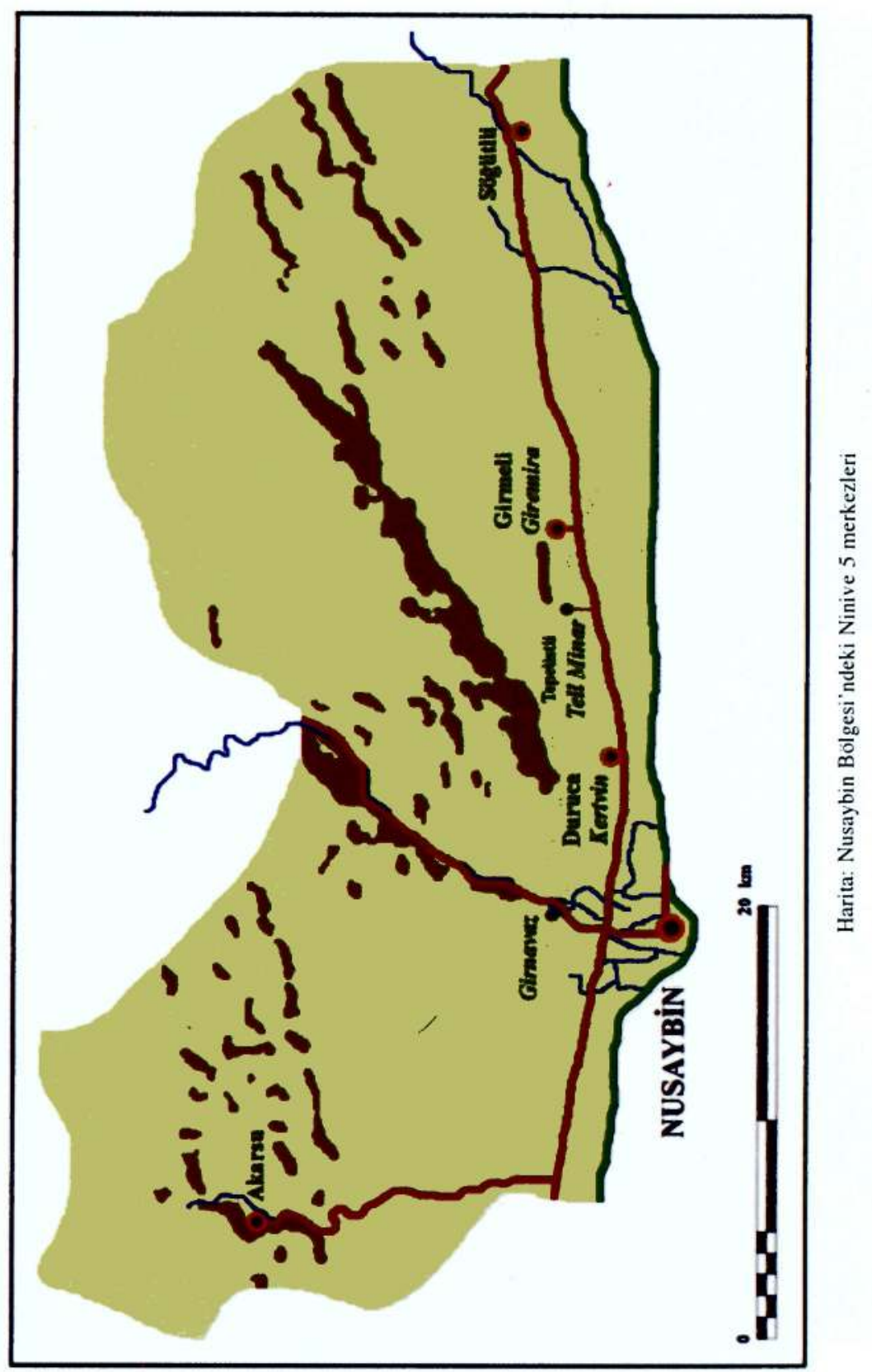




\section{Bora Uysal}

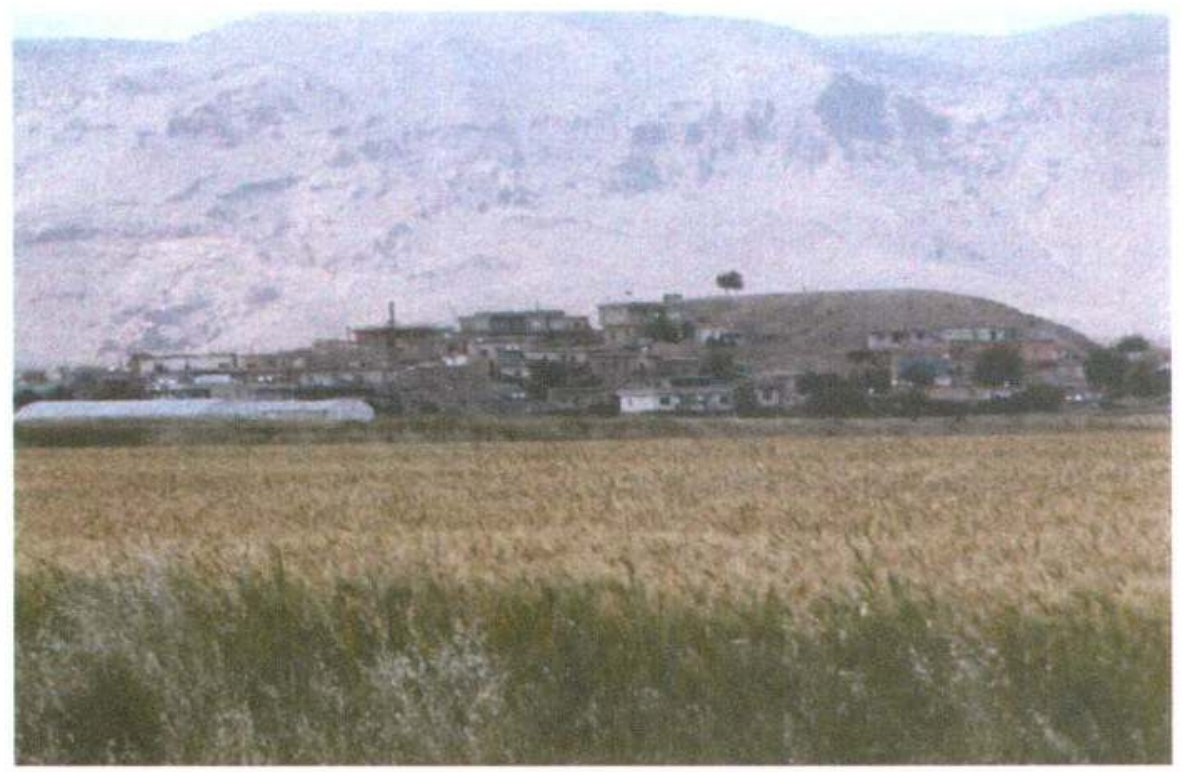

Resim I: Tell Minar 2004, güncyden görünüs

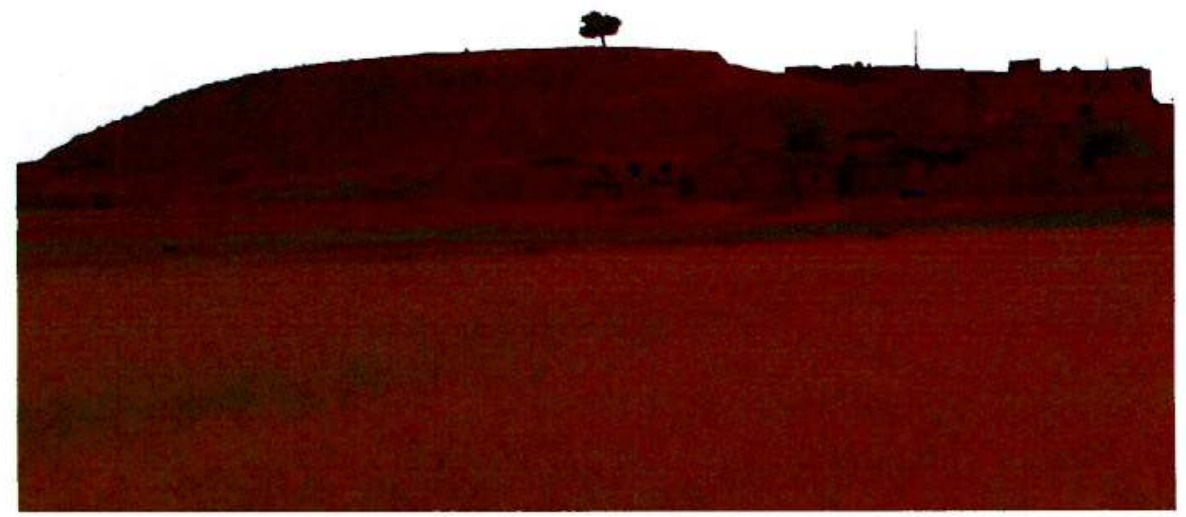

Resim 2: Tell Minar 2004, kuzeyden görünüs 


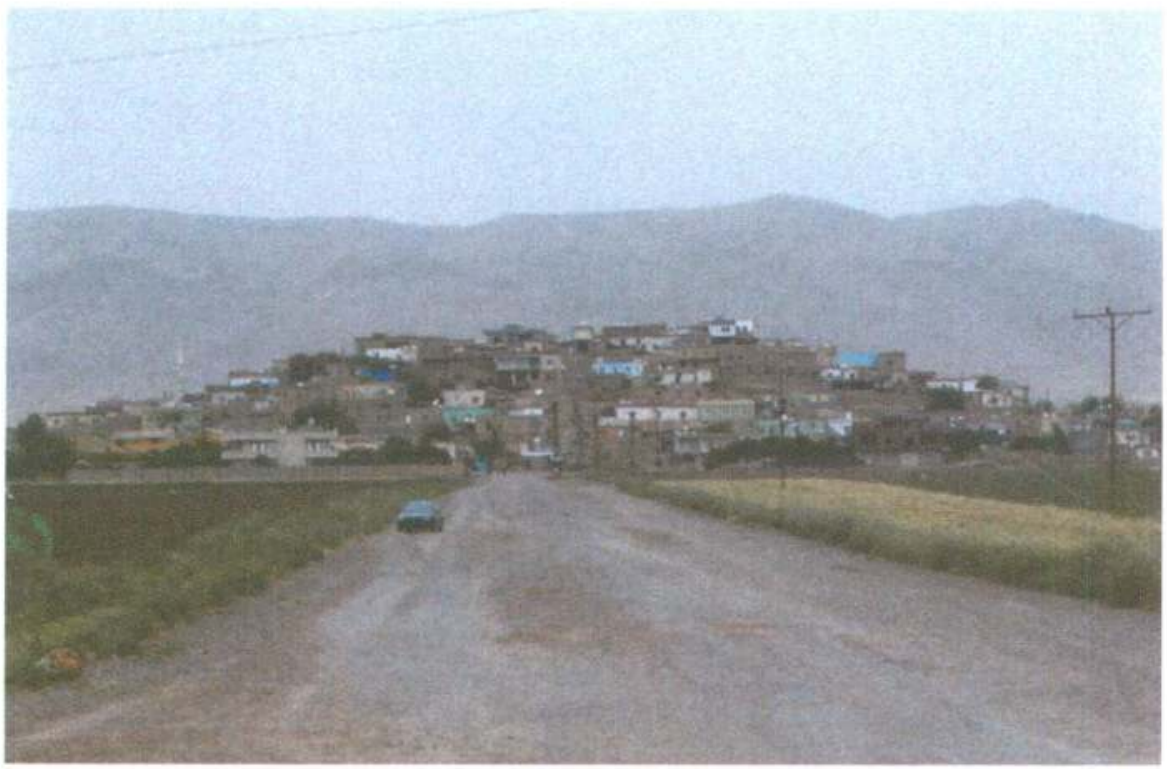

Resim 3: Giremira 2004, güneyden görünüs

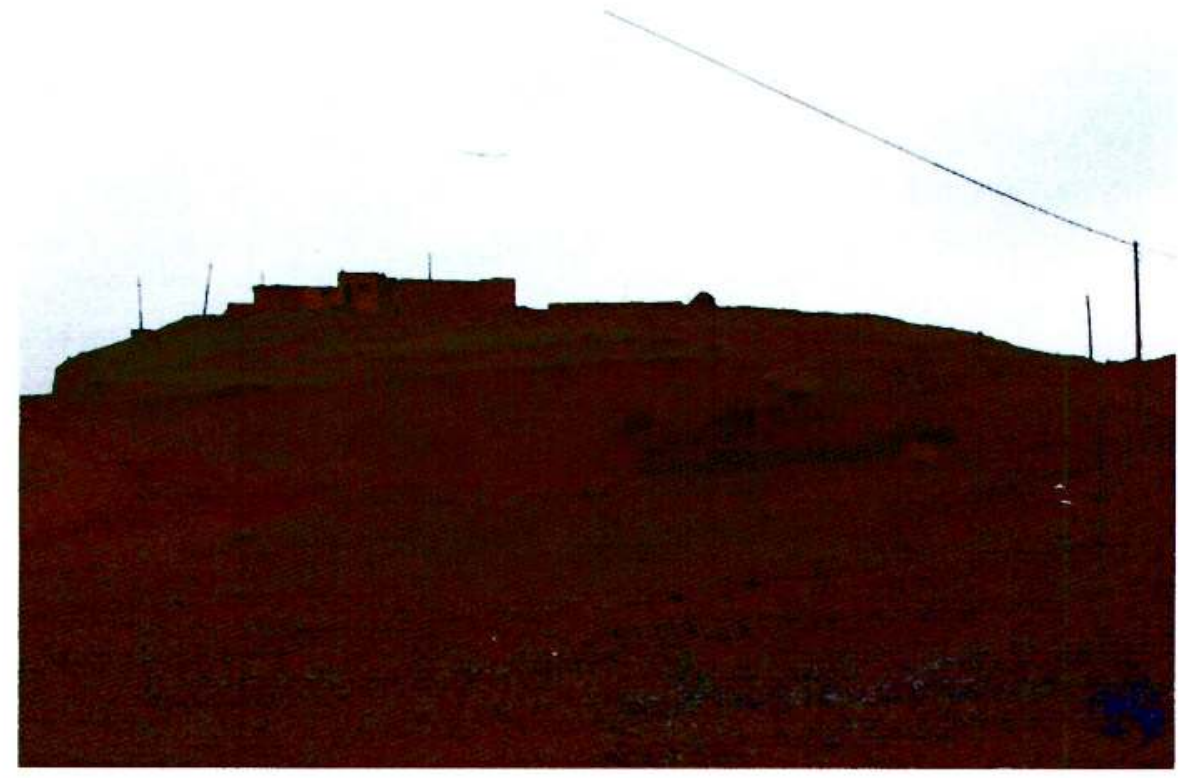

Resim 4: Giremira 2004. kuzeyden görünüs 


\section{Bora Uysal}
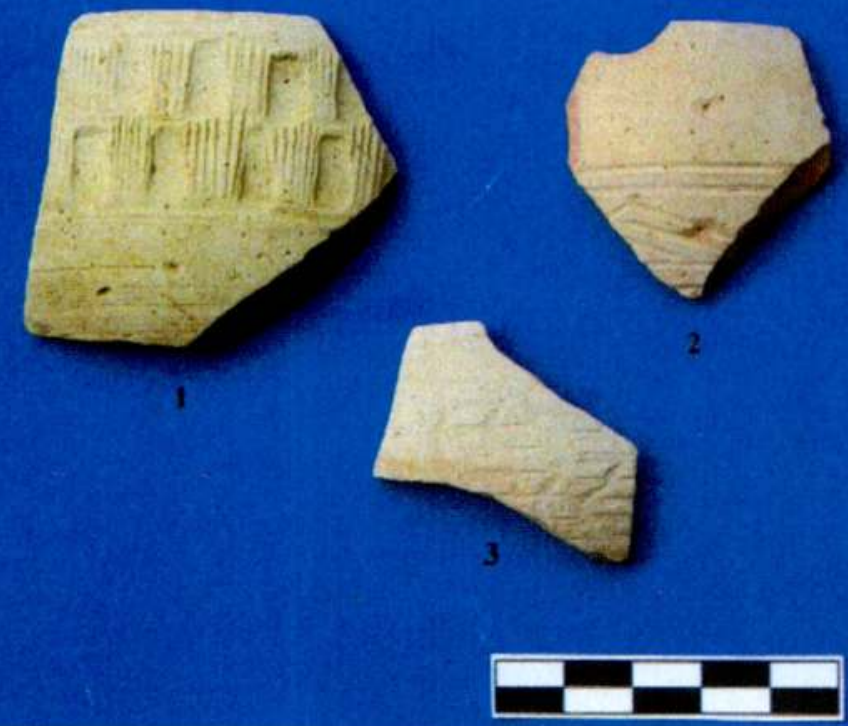

Resim 5: Tell Minar ve Giremira, çizi-oyma bezemeli Ninive 5 seramiği

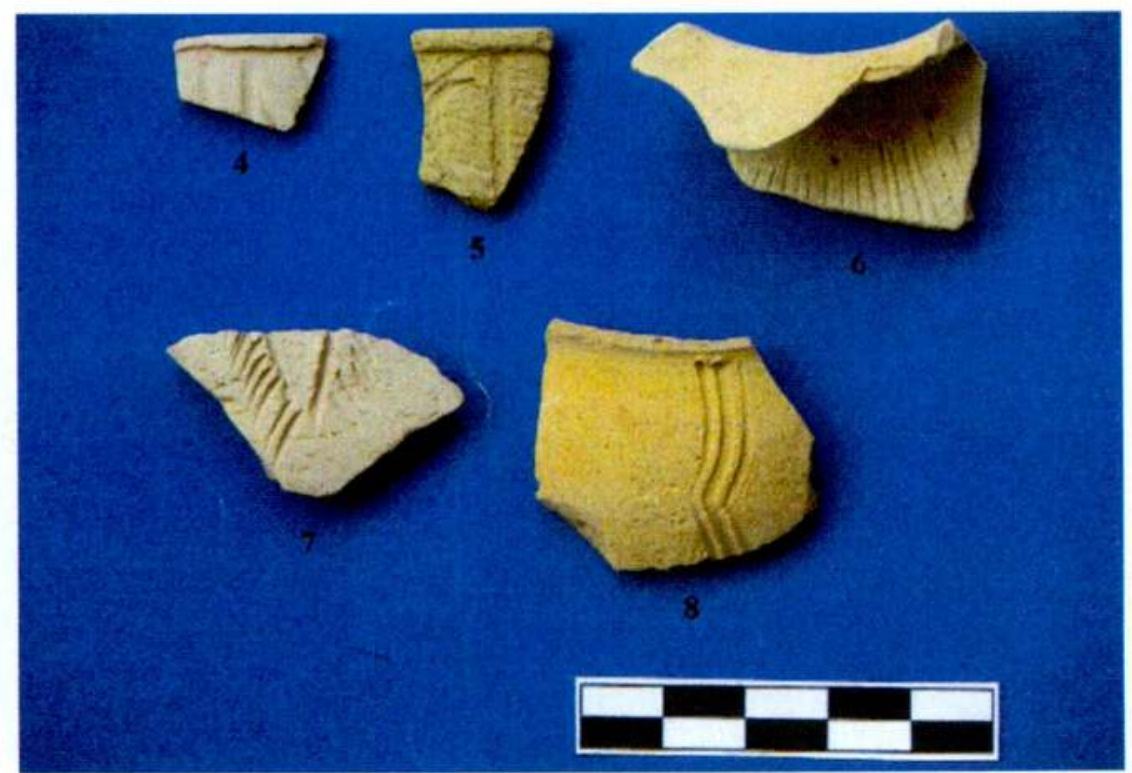

Resim 6: Tell Minar ve Giremira, çizi-oyma bezemeli Ninive 5 seramiği 
Levha I

Bora Uysal
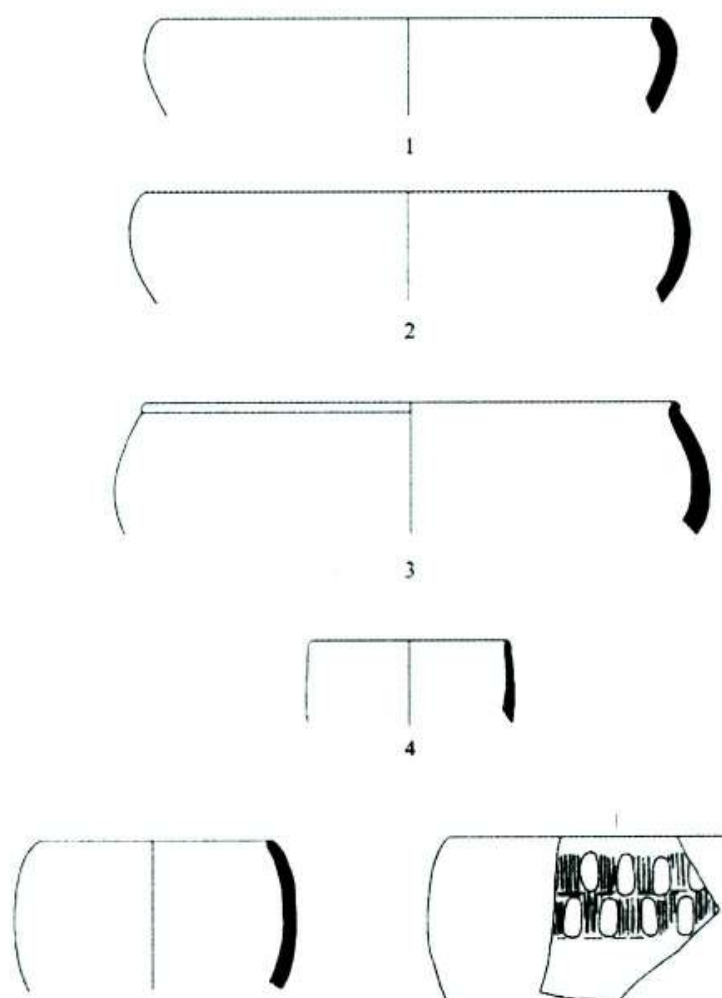

5
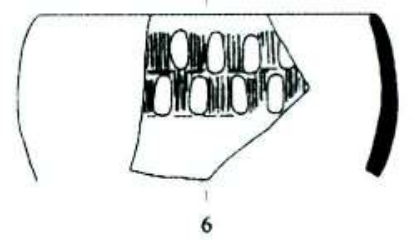

>ns

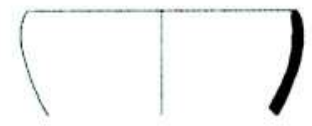

7

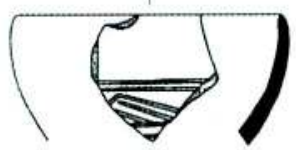

8

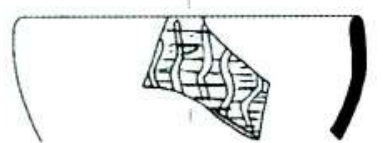

9

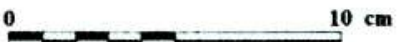



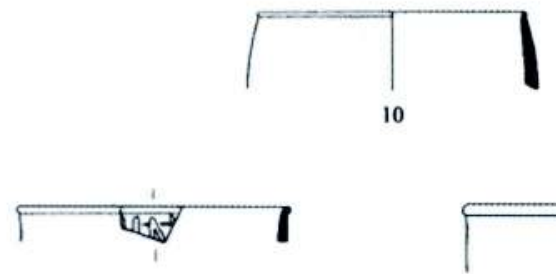

11
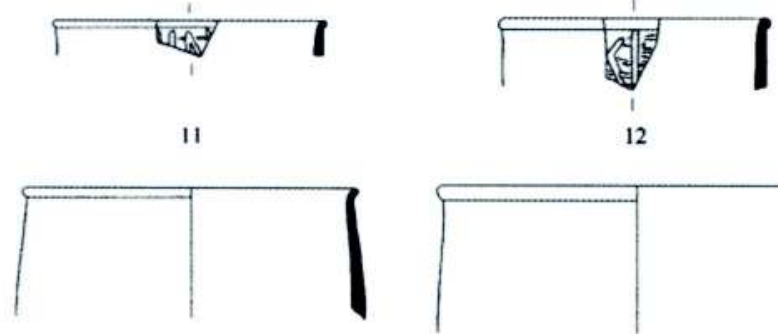

13

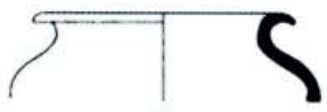

15
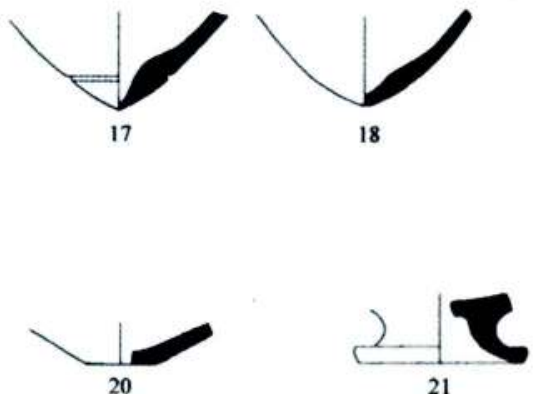

23

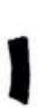

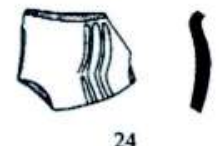

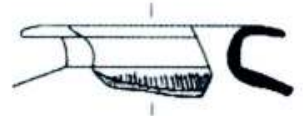

16

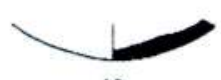

19

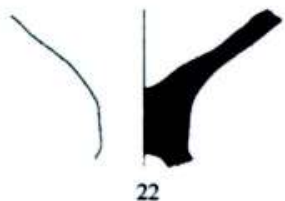

$10 \mathrm{~cm}$

0 